\title{
Patients' blood pressure knowledge, perceptions and monitoring practices in community pharmacies
}

Jennifer Y. LAM, Lisa M. GUIRGUIS

Received (first version): 31-Mar-2010 Accepted: 17-Aug-2010

\begin{abstract}
${ }^{*}$
Hypertension is a modifiable risk factor for cardiovascular disease. Despite this, patients often cannot or inaccurately estimate their risk factors. Objectives: In order to improve pharmacist interventions, we sought to: 1) find out patients' knowledge about blood pressure (BP) and their selfmonitoring behaviors and 2) identify the relationships between these two elements. Specifically, if evaluation of BP control were related to knowledge of one's BP level and self-monitoring habits, and if knowledge of one's target and BP level varied with monitoring habits.

Methods: Final year pharmacy students were trained and interviewed patients in community pharmacies as a required exercise in their pharmacy clerkship. Each student recruited a convenience sample of 5-10 patients who were on hypertension medication, and surveyed them regarding their BP targets, recent BP levels as well as monthly and home BP monitoring practices. Results: One third of the 449 patients interviewed were able to report a blood pressure target with $26 \%$ reporting a JNC 7 recognized target. Three quarters of patients who reported a blood pressure target were able to report a blood pressure level, with $12 \%$ being at their self- reported target.

Roughly two thirds of patients perceived their BP to be "about right", and slightly less than a third thought it to be "high". Sixty percent of patients monitor their BP monthly, but less than $50 \%$ of patients practice home BP monitoring.

Conclusions: This study along with others before it point to the knowledge and self-management gaps in patients with chronic conditions. Furthermore, pharmacy students were able to use a brief intervention to screen patients during routine care. Pharmacists can help improve patient understanding and promote increased selfmanagement through regular BP monitoring.
\end{abstract}

Keywords: Students, Pharmacy. Blood Pressure Monitoring, Ambulatory. Self Care. Hypertension. Canada.

\footnotetext{
*Jennifer Y. LAM. Student of Pharmacy, Faculty of Pharmacy and Pharmaceutical Sciences, University of Alberta. Edmonton (Canada).

Lisa M. GUIRGUIS. PhD. Assistant Professor, Faculty of Pharmacy and Pharmaceutical Sciences, University of Alberta. Edmonton (Canada).
}

\author{
CONOCIMIENTO, PERCEPCIONES Y \\ PRÁCTICAS DE MONITORIZACIÓN EN \\ FARMACIAS COMUNITARIAS DE LOS \\ PACIENTES SOBRE LA PRESIÓN \\ ARTERIAL
}

\section{RESUMEN}

La hipertensión es un factor de riesgo modificable para enfermedades cardiovasculares. A pesar de esto, a menudo los pacientes son incapaces o estiman inadecuadamente sus factores de riesgo. Objetivos: Para mejorar las intervenciones farmacéuticas, tratamos de 1) averiguar el conocimiento de los pacientes sobre presión arterial (PA) y sus comportamientos de automonitorización, y 2) identificar las relaciones entre estos dos elementos. Específicamente, si la evaluación de la PA estaba relacionada con el conocimiento de uno de los niveles de PA y los hábitos de auto-monitorización, y si el conocimiento de uno de los objetivos y niveles de PA variaba con los hábitos de monitorización. Métodos: Se entrenó a los estudiantes del último año de farmacia y entrevistaron pacientes en farmacias comunitarias como ejercicio obligatorio en sus prácticas. Cada estudiante reclutó una muestra de conveniencia de 5 a 10 pacientes que estaban con medicación para hipertensión, y se les entrevistó en relación a sus objetivos de PA, valores recientes de PA así como en las practicas mensuales de monitorización de PA. Resultados: Un tercio de los 449 pacientes entrevistados fueron capaces de comunicar sus objetivos de PA con un $26 \%$ de reportes de un objetivo reconocido en el 7-JNC. Tres cuartos de los pacientes que respondieron un objetivo de PA fueron capaces de informar de su valor de PA, con un $12 \%$ que se encontraba en sus objetivos de PA relatados. Aproximadamente dos tercios de los pacientes percibía que su PA estaba "más o menos bien" y algo menos de un tercio que estaba "alta". $\mathrm{El}$ 60\% de los pacientes monitorizan su PA mensualmente, pero menos del $50 \%$ realizan monitorización domiciliaria de la PA.

Conclusiones: Este estudio, al igual que otros anteriores, señala brechas en el conocimiento y en la auto-gestión de los pacientes de sus enfermedades crónicas. Incluso los estudiantes de farmacia fueron capaces de realizar una breve intervención para rastrear pacientes en la práctica diaria. Los farmacéuticos pueden mejorar el conocimiento y promover la auto-gestión mediante monitorizaciones regulares de la presión arterial. 
Palabras clave: Estudiantes de farmacia.

Monitorización ambulatoria de la presión arterial. Auto-cuidados. Hipertensión. Canadá.

\section{INTRODUCTION}

Hypertension is the most frequent primary diagnosis in the United States and affects 1 billion people worldwide. It is associated with numerous conditions including diabetes, renal morbidity, stroke and other cardiovascular events. Fortunately, the consequences of lowering blood pressure (BP) have equally dynamic effects, with a decline in the incidence of myocardial infarction of $20-25 \%$ and cerebral vascular events of $35-40 \%$ with proper treatment. ${ }^{1}$ Still, patients frequently incorrectly assess actual risks, with up to $46 \%$ of hypertensive or diabetic patients overestimating their risks, and $23 \%$ unable to provide an estimation of their risk factors. ${ }^{2}$

National Guidelines ${ }^{3}$ state that simple and ongoing intervention by a team of health professionals can significantly improve adherence to lifestyle modifications. Pharmacists' involvement as member of the health care team in drug monitoring has markedly reduced patient $\mathrm{BP}{ }^{4-8}$ Pharmacists are one of the most accessible health care professionals, and as such are optimally positioned $^{9-12}$ to monitor drug therapy and selfmonitoring practices $^{13}$, to support better clinical outcomes. ${ }^{13,15}$

Although hypertension is often described as a silent disease, many patients actively manage their antihypertensive medications. In one sample of 623 patients with hypertension, one third self-initiated a reduction in dose or eliminated their hypertension medications. ${ }^{16}$ These patients may have benefited from the support of a pharmacist's medication expertise. Pharmacists' contributions are not limited to drug information, but could also include disease education, encouragement of greater patient responsibility, use of drug compliance aids and implementation of BP monitoring programs as a part of a comprehensive approach to hypertension management.

In order to improve pharmacists' care for patients with hypertension, the patients' understanding of hypertension and self- monitoring practices need to be better understood. Three studies examined the knowledge of personal BP readings and target levels, as well as self- management techniques of patients with hypertension and/or diabetes in the community. $9,17,18$ The data in all three studies were collected via patient self- report in response to direct questioning or self administered questionnaires in either a medical clinic or community pharmacy. Between $39-68 \%$ of patients were aware of their BP values, while only $20-30 \%$ of patients were able to recall their targeted $\mathrm{BP} .^{9,17,18}$ Patient education on target BP and hypertension- associated health risks were found to be a significant predictor of self BP awareness and monitoring habits $^{9}$, indicating a need for pharmacists to take an increased role in patient- directed hypertension care.

In order to obtain a better understanding of patient perceptions of their BP levels, goals and monitoring practices in the community, we conducted a cross sectional survey of patients who were on medications to control hypertension and included an assessment of patients' self monitoring practices. Our methodology utilizes a face to face patient encounter which, similar to the study by Guirguis et al. ${ }^{18}$, may allow for content clarification by the patient, hence improving reporting accuracy by patients.

This primary objective of this research is to describe the knowledge and self-monitoring practices of a sample of patients recruited in a community pharmacy. Specifically, we would determine: 1) the proportion of patients with hypertension who reported a BP target and level, 2) the proportion of patients at national targets for BP, and 3 ) patients' self-monitoring practices.

Secondary objectives address the relationships between patients': 1) evaluation of their BP control and knowledge of a BP level, 2) perceptions about their BP and self monitoring practices, and 3 ) knowledge of BP levels / targets and BP selfmonitoring habits.

\section{METHODS}

Pharmacy students in their final year gathered data from a required exercise as part of their Ambulatory Pharmaceutical Care Clerkship in a one year period. The project was reviewed and approved by the University of Wisconsin-Madison Health Sciences Institutional Review Board.

\section{Subjects}

Patients were recruited from the clerkship sites affiliated with the School of Pharmacy at the University of Wisconsin-Madison. These clerkship sites are community, chain, or clinic pharmacies. Approximately 120 student pharmacists recruited at least 5 and up to 10 patients. Student pharmacists were asked to select a convenience sample of patients who were on medication for hypertension. There were no material inducements.

\section{Data Collection}

Student pharmacists were trained on data collection and provided with written directions and an interview guide to ensure that information was gathered systematically. Pharmacy managers were asked to consent to data collection at their site. Student pharmacists approached patients on antihypertensive medications during regular pharmacy activities, asked patients to share their BP levels and target numbers, recorded information on the interview guide, and provided an information sheet and monitoring log on BP provided by the American Heart Association. They are titled: "What is High BP?" and "BP Tracker". ${ }^{19,20}$ These tools promote targets set by the Joint National Committee on Prevention, Detection, Evaluation, and Treatment of High BP (JNC 7). ${ }^{1}$ After the interview was 
administered, pharmacy students asked patients for verbal consent to share their BP information data for research and provided patients with a written study information sheet. Students then transcribed data from the interview guide onto a secure online website. Students were asked to transcribe the data as patients reported it and include "DK" for Don't Know.

While students were encouraged to make recommendations to their patients and patients' other health care providers with patients' permission if the hypertension control was sub-optimal, this was not a required part of the assignment.

\section{Analysis}

All data were analyzed with SPSS version 13.0. An alpha of 0.05 was used to evaluate all statistical tests. Implausible levels or target numbers were coded as missing. For example, a BP level of "300/600" was coded as missing. Descriptive statistics were used to characterize the data from the interview guide including patients' self-reported knowledge of BP, treatment goals, and demographics. Patients' self- reported BP levels were compared to patients' self-reported clinical goals and targets in the JNC 7 to identify patients who are above targets. ${ }^{1}$ Chi-square analysis was used to test secondary objectives about relationships between knowledge of $\mathrm{BP}$ and selfmonitoring practices.

\section{RESULTS}

Data were gathered by students completing their community pharmacy clerkship at 39 sites in Wisconsin. 120 students approached 716 patients and of those 620 had time to talk and 449 patients consented to participate in the study (see Figure 1). Only 2 patients were diabetic, which is lower than the expected prevalence of $5-10 \%$. However in the prior year, students had approached patients regarding awareness of diabetes targets and thus patients with diabetes may have been passed over in the BP check. Thus, the data for the 2 patients with diabetes was removed, as an analysis of this subgroup would not be meaningful. Furthermore, 38 patients who received the $\mathrm{BP}$ check at least once before had their second BP check presented separately. There were no statistical differences between patient reports in the first and second BP checks (see Tables 1 to 3 ).

\section{Patient BP Knowledge and Self- Monitoring}

First, we assessed patient knowledge about their BP targets. Of the 148 first BP checks who reported a target: $34.5 \%$ of patients reported a target of $120 / 80 \mathrm{mmHg}, 11.5 \%$ reported $130 / 80 \mathrm{mmHg}$, $22.3 \%$ reported $140 / 90 \mathrm{mmHg}$ and $31.8 \%$ reported other reasonable values (see Table 1). At their second BP check, $26.4 \%$ responded with one of the three accepted targets (see Table 1). ${ }^{1}$ Over three fourths of patients were able to report a BP level (see Table 2). JNC 7 BP guidelines current at the time of the study recommend treating hypertension to $\leq 140 / 90 \mathrm{mmHg}$ (see Table 2). ${ }^{1}$ Of the 128 people who reported a BP target and level, 38.3\% met their goal (Table 3).

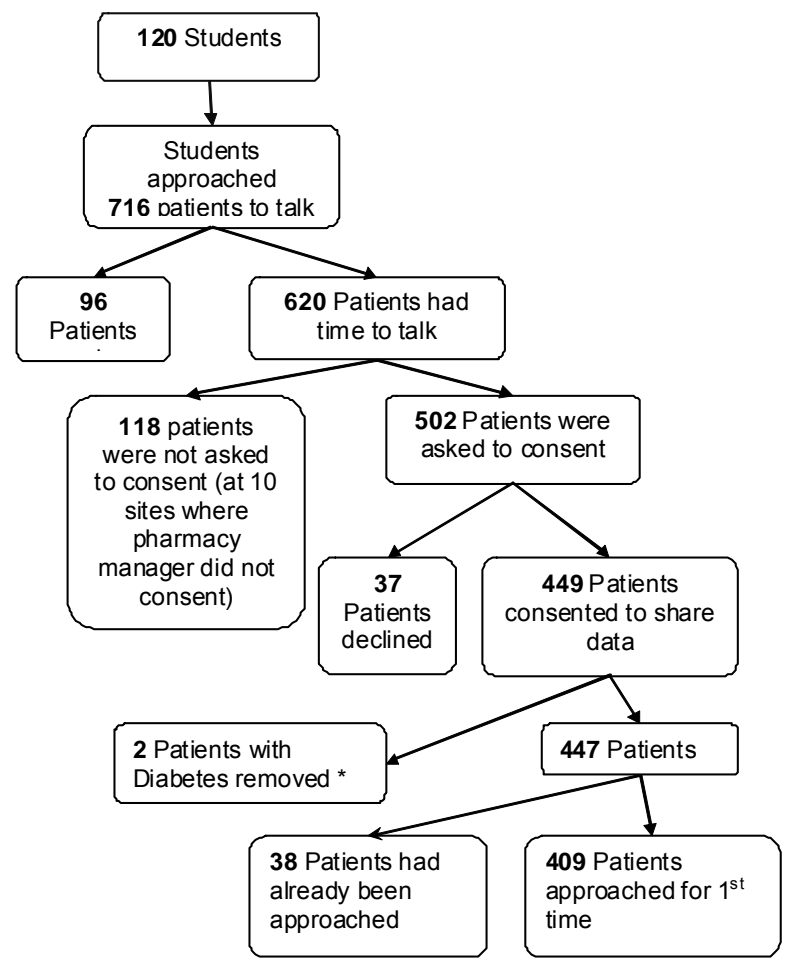

Figure 1: Blood pressure project participation * Insignificant diabetic population size

Patients were also asked to evaluate their BP as being 'high', 'low' or 'about right'. Most patients from both groups however, deemed themselves 'about right'; $65.5 \%$ of patients at their first BP check and $71.1 \%$ patients at the second BP check. About a quarter to a third felt their BP was 'high' $(30.1 \%$ and $26.3 \%$ of those respectively). Finally, few patients reported having a 'low' BP $(3.4 \%$ and $2.6 \%$ respectively).

\begin{tabular}{|c|c|c|c|c|}
\hline \multicolumn{5}{|c|}{ Table 1. Patient Reported Blood Pressure Target } \\
\hline & First BP Check & \multicolumn{2}{|c|}{$\begin{array}{c}\text { Second BP } \\
\text { Check }^{*}\end{array}$} \\
\hline Target & $\mathrm{n}$ & Percent & $\mathrm{n}$ & Percent $^{-1}$ \\
\hline $120 / 80 \mathrm{mmHg}$ & 51 & 12.5 & 6 & 15.8 \\
\hline $130 / 80 \mathrm{mmHg}$ & 17 & 4.2 & 2 & 5.3 \\
\hline $140 / 90 \mathrm{mmHg}$ & 33 & 8.1 & 2 & 5.3 \\
\hline Other & 47 & 11.5 & 6 & 15.8 \\
\hline Don't Know Target & 244 & 59.7 & 22 & 57.9 \\
\hline Missing & 17 & 4.2 & 0 & 0 \\
\hline TOTAL & 409 & $100 \%$ & 38 & 100 \\
\hline $\begin{array}{l}\text { * No statistical differences between first and second BP } \\
\text { check }\end{array}$
\end{tabular}

Students also assessed the frequency of patients' home BP monitoring; $37.7 \%$ performed self monitoring at the first BP check, compared to $47.4 \%$ of those at their second BP check. Both groups had similar habits when it came to monthly BP monitoring- $59.9 \%$ and $57.9 \%$ respectively.

Relationships between Blood Pressure Knowledge and Monitoring

The total sample of 447 BP checks was used for the secondary analysis as there were no differences between first and second BP checks in primary analyses. We found patient's evaluations of BP, 
('about right', 'high' or 'low') was not related to patients' knowledge of a BP level $(p=0.611)$.

\begin{tabular}{|c|c|c|c|c|}
\hline \multirow{2}{*}{ Table 2. Patie } & \multicolumn{2}{|c|}{ First BP Check } & \multicolumn{2}{|c|}{ Second BP Check* } \\
\hline & $\mathrm{n}$ & Percent & $\mathrm{N}$ & Percent \\
\hline $\begin{array}{c}\text { At Target } \\
(\leq 140 / 90 \\
\mathrm{mmHg})\end{array}$ & 206 & $69.4^{\dagger}$ & 21 & $77.8^{\dagger}$ \\
\hline $\begin{array}{c}\text { Not At } \\
\text { Target } \\
(>140 / 90 \\
\mathrm{mmHg})\end{array}$ & 91 & $30.6^{\dagger}$ & 6 & $22.2^{\dagger}$ \\
\hline $\begin{array}{c}\text { Don't Know } \\
\text { BP Level }\end{array}$ & 98 & $24.0^{\ddagger}$ & 9 & $23.7^{\ddagger}$ \\
\hline Missing & 14 & $3.4^{\ddagger}$ & 2 & $5.3^{\mp}$ \\
\hline TOTAL & 409 & -- & 38 & -- \\
\hline $\begin{array}{l}{ }^{*} \text { No statisti } \\
\text { check } \\
{ }^{\dagger} \text { Of those wh } \\
{ }^{\ddagger} \text { Of the total }\end{array}$ & low $t$ & BP leve & 97 & \\
\hline
\end{tabular}

\begin{tabular}{|c|c|c|c|c|}
\hline \multicolumn{2}{|c|}{ Table 3. Patients at Self- Reported Target } \\
\hline & First BP Check & \multicolumn{2}{|c|}{ Second BP Check* } \\
\cline { 2 - 5 } & $\mathrm{n}$ & Percent & $\mathrm{N}$ & Percent \\
\hline $\begin{array}{c}\text { At Self- } \\
\text { Reported } \\
\text { Target }\end{array}$ & 49 & 12.0 & 7 & 18.4 \\
\hline $\begin{array}{c}\text { Not at Self- } \\
\text { Reported } \\
\text { Target }\end{array}$ & 79 & 22.2 & 5 & 21.1 \\
\hline $\begin{array}{c}\text { Don't Know } \\
\text { Target }\end{array}$ & 258 & 60.6 & 23 & 55.3 \\
\hline Missing & 23 & 5.1 & 3 & 5.3 \\
\hline TOTAL & 409 & $100 \%$ & 38 & $100 \%$ \\
\hline $\begin{array}{c}\text { * No statistical differences between first and second BP } \\
\text { check. }\end{array}$ & \multicolumn{4}{|l}{} \\
\hline
\end{tabular}

For secondary objective 2 , patients who monitored their BP at least monthly were less likely $(p=0.02)$ to evaluate their BP as 'about right' $(61.5 \%$ who monitor vs. $73.3 \%$ who do not monitor), and more likely to think that their BP was lower $(4.9 \%$ vs. $1.2 \%$, respectively) or higher $(33.6 \%$ vs. $25.5 \%$, respectively) than those who do not monitor. There was no relationship between evaluations of $\mathrm{BP}$ control and home monitoring $(p=0.953)$.

For secondary objective 3 , knowledge of a BP target and level was related to a patient's monthly self- monitoring practices $(p=0.011$ and $p=0.001$, respectively), as well as their home monitoring habits $(p=0.0001$ and $p=0.001$, respectively). Those who monitored their BP at least monthly were more likely to know their target BP than those who did not (42.8\% vs. $30.1 \%$, respectively). Similarly, patients who monitored their BP at home also were more likely to know their target values than those who do not $(50.0 \%$ vs. $30.2 \%$ respectively). This trend is also seen in patients who were able to report a BP levels, as those who monitor monthly were more likely to know their BP than those who did not monitor regularly $(81.2 \%$ vs. $66.0 \%)$. This relationship is similar in those who monitored at home; $84.3 \%$ know their levels versus $69.4 \%$ of those who did not monitor at home.

\section{DISCUSSION}

Overall, patients identified through community pharmacies had limited knowledge about national $\mathrm{BP}$ goals and personal BP targets. Although many knew their BP levels, a poor awareness of target guidelines meant that they may be unable to interpret their risk. Similar to Guirguis et al. ${ }^{18}$, threequarters of patients could report a BP level, yet only $40 \%$ were aware of their target. Thus, $30 \%$ of patients may not be able to evaluate their progress. Only a quarter were able to report one of the three recognized JNC 7 target guidelines ${ }^{1}$, and a second questioning of a smaller population of the same group only saw no improvement. However, these results are considerably higher than those found in a similar study by Lau et al., who reported that only $8.9 \%$ of a geriatric patient population knew of an acceptable target. $^{9}$ In contrast, Guirguis et al. reported that $35 \%$ of patients were able to provide a recognized target. ${ }^{18}$ The discrepancies between these values may be attributed to the larger age demographic of our sample (ie. not restricted to geriatrics), as well as the exclusion of patients with diabetes. In analyzing patient's ability to identify targets, we could not to take into account the possibility that patients may have had physicianmodified targets as a result of concurrent medical conditions.

Of those who reported a target, more than a third were at their target BP, which is comparable to results found by Whitley et al. (37\% achieving goal $)^{17}$, and Guirguis et al (34.8\% at goal). ${ }^{18}$ This suggests that although patients are more inclined to know their personal BP levels, this knowledge can be without regard to knowledge of a target goal. Furthermore, the majority of patients surveyed $(65.5 \%-71.1 \%)$ had the perception that their BP levels were 'about right'. However these perceptions may not be indicative of actual BP levels and may place patients at risk of poor medication adherence. $^{16}$

Patient evaluation of BP control (i.e., high, low, or about right) did not vary with knowledge of a BP level. This could have occurred for three reasons: firstly, patients may have only been provided with a global perception of their BP -high, low, or about right. Thus, remembering a BP level did not correlate with their ability to evaluate their BP. This knowledge may be sufficient to motivate activities to promote BP control; although it merits further study. Secondly, perceptions of BP control may be derived from factors other than BP levels. Patients may form perceptions of BP control based on their perceived physiological signs and symptoms of BP such as headache or dizziness. We were unable to determine if patients' perceptions reflected their true BP levels as we did not obtain an objective measure of BP. Third, this may also be indicative of low health literacy. It is estimated that $78 \%$ of people are unable "to obtain, process, and understand basic health and medication information and [services] needed to make appropriate health decisions". ${ }^{21}$ Future research should consider a measure of health literacy to investigate the role of 
health literacy on patients' BP knowledge and assessment.

Despite these findings, patients who knew their BP level and/or target also were more likely to monitor their BP. We do not know which variable is the causative factor. This is similar to work by Lau et al., which demonstrated knowledge of target BP is an independent predictor of self monitoring.

Further analysis found no differences between the data sets of the first and second BP check groups. This could be attributed to several possible reasons, the first being that the second group had a small sample size. Secondly, the study was not intended to have patients interviewed more than once and lastly, time between visits may have been insufficient for measurable change.

Implications for Practice

Pharmacists may find that patients who monitor their BP monthly may be less inclined to have a complacent perception towards their hypertensive therapy. The data provided by monitoring may allow pharmacists to provide personalized care. There is also a role for pharmacists to screen patients with poorly managed hypertension through minimal interventions (ie. similar to our self- report survey) and promote self- monitoring to those who may be suitable. This study along with others before $\mathrm{it}^{9,17,18}$, point to the knowledge gaps present in patients with chronic conditions. Pharmacists can remedy this by enhancing patient understanding of hypertension with the goal of improving medication adherence and patient health.

There is a need to investigate the relationship between patients' BP control evaluations (i.e., high, low, or about right) and their objective BP control. In practice, pharmacists may need to know if patients who perceive their BP to be 'about right' are correct in their assumption. Patients' perceptions of BP may influence their medication taking, BP monitoring and lifestyle.

\section{Limitations}

There are several limitations to our research. First, the use of convenience sampling may skew our results such that they are not generalizable to the larger hypertensive population. Students may also be predisposed to selecting patients that appear more approachable or receptive. Despite this, our selection strategy is reflective of current pharmacy practice. Second, a patient's social desirability and recall error likely affects the accuracy of their reported levels in self- reported data. Yet in light of this, one- third of patients still reported levels that were not on target. The advantage of self- report data is that it allows practitioners to identify the patient's understanding and provides insight on knowledge gaps. Furthermore, it allows for content clarification during a face- to- face interaction. Third, when analyzing the data, we did not take into account adjustment of individual BP targets that may have been as a result of other comorbidities. Consequently, more patients may have been 'at target', though this target may not be one that is recognized by JNC 7 guidelines.

\section{CONCLUSIONS}

In community pharmacies, $63 \%$ of patients were able to recall a BP Level and $37 \%$ reported a blood pressure target. Only $12 \%$ of patients met their selfreported target; while two thirds felt their BP was about right. Sixty percent of patients monitor their BP monthly, but less than $50 \%$ of patients practice home BP monitoring. This study along with others before identified knowledge gaps in patients with chronic conditions. Pharmacists can help to enhance patient understanding and promote increased self-management through regular BP monitoring.

\section{CONFLICT OF INTEREST}

There are no conflicts of interest to be disclosed.

Sources of support: Canadian Institutes of Health Research Health Professional Student Research Award.

\section{References}

1. Chobanian AV, Bakris GL, Black HR, Cushman WC, Green LA, Izzo Jr JL, Jones DW, Materson BJ, Oparil S, Wright Jr. JT, Roccella EJ. Seventh report of the joint national committee on prevention, detection, evaluation, and treatment of high blood pressure. Hypertension. 2003;42(6):1206-1252.

2. Frijling BD, Lobo CM, Keus IM, Jenks KM, Akkermans RP, Hulscher MEJL, Prins A, Van Der Wouden JC, Grol RPTM. Perceptions of cardiovascular risk among patients with hypertension or diabetes. Patient Educ Couns. 2004;52(1):4753.

3. Onysko J, Maxwell C, Eliasziw M, Zhang JX, Johansen H, Campbell NRC. Large increases in hypertension diagnosis and treatment in Canada after a healthcare professional education program. Hypertension. 2006;48(5):853-860.

4. Chabot I, Moisan J, Gregoire J, Milot A. Pharmacist intervention program for control of hypertension. Ann Pharmacother. 2003;37(9):1186-1193

5. Roughead EE, Semple SJ, Vitry Al. Pharmaceutical care services: A systematic review of published studies, 1990 to 2003, examining effectiveness in improving patient outcomes. Int J Pharm Pract. 2005;13:53-70.

6. Erickson SR, Slaughter R, Halapy H. Pharmacists' ability to influence outcomes of hypertension therapy. Pharmacotherapy. 1997;17(1):140-147.

7. Zillich AJ, Sutherland JM, Kumbera PA, Carter BL. Hypertension outcomes through blood pressure monitoring and evaluation by pharmacists (HOME study). J Gen Intern Med. 2005;20(12):1091-1096. 
8. Lee JK, Grace KA, Taylor AJ. Effect of a pharmacy care program on medication adherence and persistence, blood pressure, and low-density lipoprotein cholesterol: A randomized controlled trial. JAMA. 2006;296(21):2563-2571.

9. Lau E, Kaczorowski J, Karwalajtys T, Dolovich L, Levine M, Chambers L. Blood pressure awareness and self-monitoring practices among primary care elderly patients. Canadian Pharmacists Journal. 2006;139(6):34-41.

10. Carter B, Helling D. Ambulatory care pharmacy services: Has the agenda changed? Ann Pharmacother. 2000;34(6):772-787.

11. Carter BL, Barnette DJ, Chrischilles E, Mazzotti GJ, Asali ZJ. Evaluation of hypertensive patients after care provided by community pharmacists in a rural setting. Pharmacotherapy. 1997;17(6):1274-1285.

12. Tsuyuki RT, Semchuk W, Poirier L, Killeen RM, McAlister FA, Campbell N, Drouin D, Lewanczuk RZ. 2006 Canadian Hypertension Education Program Guidelines for the management of hypertension by pharmacists. Canadian Pharmacists Journal. 2006;139(3 suppl.1):S11-S13.

13. Kjome RLS, Granas AG, Nerhus K, Sandberg S. Quality assessment of patients' self- monitoring of blood glucose in community pharmacies. Pharm Pract (Internet). 2010;8(1):62-69.

14. Kicklighter CE, Nelson KM, Humphries TL, Delate T. An evaluation of a clinical pharmacy-directed intervention on blood pressure control. Pharm Pract (Internet). 2006;4(3):110-116.

15. Franic D, Pathak DS, Mott D. Pharmaceutical care and health outcomes in community settings: Matched pair analysis of perceptions of hypertensive patients versus pharmacists. Pharm Pract Manag Q. 1999;19(2):1-17.

16. Wallenius SH, Vainio KK, Korhonen MJH, Hartzema AG, Enlund HK. Self-initiated modification of hypertension treatment in response to perceived problems. Ann Pharmacother 1995;29(12):1213-1217.

17. Whitley HP, Fermo JD, Ragucci K, Chumney EC. Assessment of patient knowledge of diabetic goals, self- reported medication adherence, and goal attainment. Pharm Pract (Internet). 2006;4:183-190.

18. Guirguis LM, Kieser MA, Chewning BA, Kanous NL. Recall of A1C, blood pressure, and cholesterol levels among community pharmacy patients with diabetes. J Am Pharm Assoc. 2007;47(1):29-34.

19. American Heart Association. What is High Blood Pressure? [Internet]. Dallas (TX): American Heart Association; [updated 2008; cited 2010 March 25]. Available from: http://www.americanheart.org/presenter.jhtml?identifier=3004828.

20. American Heart Association. BP Tracker. [Internet]. Dallas (TX): American Heart Association; [updated 2007; cited 2010 March 25].Available from: http://www.americanheart.org/presenter.jhtml?identifier=3002530.

21. Agency for Healthcare Research and Quality. [Internet]. Rockville (MD): Agency for Healthcare Research and Quality; [citied 2010 March 29]. Available from: http://pharmacyhealthliteracy.ahrq.gov/sites/PharmHealthLiteracy/default.aspx. 